\title{
OBTENÇÃO DE LEITE COM TEOR REDUZIDO DE FENILALANINA PELA AÇÃO DA PROTEASE DO Aspergillus sojae E USO DO CARVÃO ATIVADO
}

\author{
SOUZA, Mariana Wanessa Santana ${ }^{1}$; LIMA, Letícia Gonçalves ${ }^{2}$; SILVA; Viviane Dias \\ Medeiros $^{3}$; SEGALL, Sérgio Duarte ${ }^{4}$; SILVESTRE, Marialice Pinto Coelho Silvestre ${ }^{5}$
}

\author{
1,2,3,5 Universidade Federal de Minas Gerais \\ Laboratório de Bromatologia, Departamento de Alimentos, Faculdade de Farmácia, \\ Av. Antônio Carlos, 6627 - Pampulha - Belo Horizonte - Minas Gerais - CEP 31270-901 \\ ${ }^{4}$ Centro Universitário de Belo Horizonte - UNIBH \\ Departamento de Ciências Biológicas, Ambientais e da Saúde - Nutrição \\ Avenida Professor Mário Werneck 1685 - Belo Horizonte, Estoril CEP: 30455-610
}

\begin{abstract}
E-mail: mwssouza@yahoo.com.br ${ }^{1}$; letglima@yahoo.com.br²; vivianedms@yahoo.com.br ${ }^{3}$; sergiosegall@yahoo.com4; malice@ farmacia.ufmg.br ${ }^{5}$
\end{abstract}

Resumo - Visando o preparo de leite com baixo teor de fenilalanina (Phe), para ser introduzido na dieta de fenilcetonúricos, inicialmente as proteínas foram hidrolisadas pela ação de uma protease do Aspergillus sojae, tendo sido testados o efeito da relação E:S, da temperatura e do tempo de reação. Posteriormente, os hidrolisados protéicos foram tratados com carvão ativado (CA) para remoção de Phe, empregando-se as relações proteína:CA de 1:22, 1:44 e 1:88. A eficiência da remoção foi avaliada por espectrofotometria derivada segunda, determinando-se o teor de Phe livre no leite e em seus hidrolisados, após tratamento com CA. Dentre todos os parâmetros estudados, o melhor resultado foi obtido ao se empregar o tempo de $3 \mathrm{~h}$, a temperatura de $50^{\circ} \mathrm{C}$, a relação E:S de 4:100 e a relação proteína:CA de 1:22, tendo atingido $64,6 \%$ de remoção e o teor final de Phe de $54,2 \mathrm{mg} / 100 \mathrm{~mL}$ de leite, permitindo assim a utilização deste alimento por pacientes fenilcetonúricos.

Palavras-chave - leite; hidrólise enzimática; carvão ativado; fenilalanina; fenilcetonúria.
Abstract - Aiming the preparation of milk with low phenylalanine (Phe) content to be introduced in the phenylketonurics' diet, its proteins were initially hydrolyzed by the action of a protease from Aspergillus sojae, and the effect of the E:S ratio, temperature and reaction time was tested. Then, the protein hydrolysates were treated with activated carbon (AC) for removing Phe, using protein:AC ratios of 1:22, 1:44 and 1:88. The efficiency of Phe removal was evaluated by second derivative spectrophotometry, determining the Phe content in milk and in its hydrolysates, after treatment with AC. Among all the parameters studied, the best result was obtained when using a reaction time of $3 \mathrm{~h}$, a temperature of $50^{\circ} \mathrm{C}$, an $\mathrm{E}: \mathrm{S}$ ratio of $4: 100$ and a protein: $\mathrm{AC}$ ratio of $1: 22$, reaching $64.6 \%$ of Phe removal and a final Phe content of $54.2 \mathrm{mg} / 100 \mathrm{~mL}$ of milk, which allows the use of this food by phenylketonurics patients.

Keywords - milk; enzymatic hydrolysis; activated carbon; phenylalanine; phenylketonuria. 


\section{INTRODUÇÃO}

A fenilcetonúria é uma doença genética, causada por uma mutação no gene que codifica a enzima fenilalanina hidroxilase, ativa no fígado e responsável pela transformação de fenilalanina (Phe) em tirosina (Tyr). O tratamento da fenilcetonúria é realizado, principalmente, através de uma alimentação restrita em alimentos protéicos naturais, e no controle na ingestão de Phe, utilizando-se fórmulas constituídas de misturas de aminoácidos livres, isentas de Phe. Entretanto, por serem importadas, essas formulações são de alto custo, além de resultarem em uma dieta monótona e pouco palatável [1,2]

O leite ocupa um lugar relevante na alimentação do brasileiro, especialmente devido às suas propriedades nutritivas, no entanto, sua introdução na alimentação de fenilcetonúricos é proibida. Neste sentido, seria de grande interesse desenvolver um leite contendo teor reduzido de fenilalanina, para que pudesse ser incorporado na dieta de fenilcetonúricos, atendendo, assim, a grande demanda que vai desde a infância até a fase adulta [3].

O processo de remoção de fenilalanina consiste, basicamente, de duas etapas: a liberação da Phe do material protéico e sua posterior remoção. A liberação da Phe se dá através da hidrólise química ou enzimática, e a remoção é feita por tratamentos diferenciados, empregando-se diversos métodos, como adsorção em carvão ativado (CA) ou resinas de adsorção [4,5,6,7,8,9,10,11], cromatografia de troca iônica, peneira molecular, filtração em gel, além de desaminação deste aminoácido pela enzima fenilalanina amônia liase. A escolha do método deve considerar a relação custo/eficiência, a praticidade e a reprodutibilidade [1].

O laboratório de Bromatologia/ Pesquisa da UFMG tem realizado estudos de remoção de Phe do soro de leite e do leite, que diferentemente do presente trabalho, foi empregado na forma de pó e desnatado e sob condições de hidrólise e remoção de Phe diferenciadas (menores concentrações de matéria-prima, maiores relações enzima: substrato e maiores quantidades de CA), usando carvão ativado ou resinas como meio adsorvente [4,8,12,13]. Nos trabalhos de remoção de Phe de cereais, realiza-se a extração prévia da proteína por métodos químicos ou enzimáticos $[7,14,15,16]$. O CA e uma resina de adsorção foram testados, anteriormente, no Laboratório de Bromatologia/Pesquisa da UFMG, tendo sido eficientes na remoção de Phe de hidrolisados protéicos de fontes diversas e empregando condições de hidrólise variadas $[4,7,8,9,11,12,14,17]$.

A avaliação da remoção de Phe é feita pela quantificação deste aminoácido na matéria-prima e nos seus hidrolisados protéicos, após o tratamento com CA. A quantificação do teor de Phe final pode ser feita por diferentes métodos, destacando-se a espectrofotometria derivada segunda (EDS) $[18,19,20,21,22]$. A EDS tem sido utilizada em diversos estudos realizados no Laboratório de Bromatologia/Pesquisa da Faculdade de Farmácia da UFMG, para a quantificação de Phe em hidrolisados protéicos obtidos pela ação de várias proteases e fontes protéicas $[6,7,8,11,14,15,23,24,25,26,27]$.

O presente trabalho representa um passo relevante no processo de obtenção de leite com teor reduzido de Phe para ser introduzido na alimentação de fenilcetonúricos. Neste sentido, este estudo teve como objetivos otimizar a remoção de Phe do leite, empregando-se na hidrólise de suas proteínas uma protease do Aspergillus sojae, e verificando-se o efeito de diversos parâmetros neste processo, tais como relação enzima:substrato, tempo e temperatura de reação. Além disso, estudou-se a influência da relação proteína:CA no processo de remoção de Phe pelo carvão ativado.

\section{MATERIAL E MÉTODOS}

\section{MATERIAL}

O leite integral UHT (Itambé, Pará de Minas, Minas Gerais) foi adquirido no comércio de Belo Horizonte, MG, Brasil. A 
protease de Aspergillus sojae (Corolase ${ }^{\circledR}$ LAP, amino-exopeptidase - EC 3.4.11.1, atividade 63,9 U/mL, pH ótimo entre 6 e 9, temperatura ótima entre 55 e $70{ }^{\circ} \mathrm{C}$ ), foi cedida pela AB Enzymes Brasil Comércio Ltda (Barueri, SP, Brasil). O carvão ativado (CA) com três diferentes granulometrias $(20$ x 50 mesh, $12 \times 25$ mesh, $6 \times 12$ mesh série Tyler) foi adquirido da Carbomafra S.A. (Curitiba, PR, Brasil). Os demais reagentes foram de grau analítico.

\section{MÉTODOS}

\section{Determinação da composição química do leite}

A composição química do leite foi determinada segundo as metodologias descritas pela Association of Official Analytical Chemists [28], sendo todas as análises realizadas em triplicatas. $\mathrm{O}$ teor de umidade foi determinado por dessecação em estufa ventilada (Quimis Q-314M242 série 020, Diadema, SP) a $105{ }^{\circ} \mathrm{C}$ até peso constante; o teor de proteína, pelo método de micro-Kjeldahl utilizando 6,38 como fator de conversão de nitrogênio total para proteína total [29]; os minerais, por incineração em mufla a $550{ }^{\circ} \mathrm{C}$ e os lipídeos foram determinados pelo método de BLIGH \& DYER (1959) [30]. O teor de carboidratos foi calculado pela diferença entre 100 e a soma das porcentagens de água, proteínas, lipídeos totais e cinzas totais.

\section{Hidrólise enzimática das proteínas do leite}

Empregando-se a enzima de Aspergillus sojae para hidrolisar as proteínas do leite, foram obtidos 16 hidrolisados, tendo sido variados os seguintes parâmetros: temperatura, tempo de reação e relação enzima:substrato (Tabela 1). Inicialmente, $50 \mathrm{~mL}$ de leite foram colocados em erlenmeyer e o $\mathrm{pH}$ medido $(6,7)$. Em seguida, levou-se ao banho de vaselina líquida, sobre agitador magnético, com agitação constante, para que fosse atingida a temperatura a ser avaliada. Após a estabilização da temperatura, adicionou-se a enzima na quantidade suficiente para atingir a relação E:S desejada. Ao final da reação, o processo foi interrompido por aquecimento em banho-maria a $75{ }^{\circ} \mathrm{C}$ por 15 segundos, a fim de inativar a enzima, confirmado pela medida da atividade enzimática antes e após o tratamento térmico, pelo método de DIAS et al. (2008) [31].

Tabela 1

Parâmetros empregados no preparo dos hidrolisados protéicos de leite e na remoção de fenilalanina

\begin{tabular}{|c|c|c|c|c|}
\hline \multirow{2}{*}{ Hidrolisados } & \multicolumn{3}{|c|}{ Hidrólise enzimática } & \multirow{2}{*}{$\begin{array}{c}\text { Remoção de } \\
\text { Phe } \\
\text { Relação } \\
\text { proteína:CA }\end{array}$} \\
\hline & Temperatura & Tempo & $\mathrm{E}: \mathrm{S}$ & \\
\hline $\mathrm{H} 1$ & $30^{\circ} \mathrm{C}$ & $1 \mathrm{~h} 30 \mathrm{~min}$ & 1 & $1: 22$ \\
\hline $\mathrm{H} 2$ & $30^{\circ} \mathrm{C}$ & $3 \mathrm{~h}$ & 1 & $1: 22$ \\
\hline H3 & $30^{\circ} \mathrm{C}$ & $5 \mathrm{~h}$ & 1 & $1: 22$ \\
\hline $\mathrm{H} 4$ & $50^{\circ} \mathrm{C}$ & $1 \mathrm{~h} 30 \mathrm{~min}$ & 1 & $1: 22$ \\
\hline H5 & $50^{\circ} \mathrm{C}$ & $3 \mathrm{~h}$ & 1 & $1: 22$ \\
\hline H6 & $50^{\circ} \mathrm{C}$ & $5 \mathrm{~h}$ & 1 & $1: 22$ \\
\hline $\mathrm{H} 7$ & $30^{\circ} \mathrm{C}$ & $1 \mathrm{~h} 30 \mathrm{~min}$ & 2 & $1: 22$ \\
\hline H8 & $30^{\circ} \mathrm{C}$ & $3 \mathrm{~h}$ & 2 & $1: 22$ \\
\hline H9 & $30^{\circ} \mathrm{C}$ & $5 \mathrm{~h}$ & 2 & $1: 22$ \\
\hline $\mathrm{H} 10$ & $50^{\circ} \mathrm{C}$ & $1 \mathrm{~h} 30 \mathrm{~min}$ & 2 & $1: 22$ \\
\hline H11 & $50^{\circ} \mathrm{C}$ & $3 \mathrm{~h}$ & 2 & $1: 22$ \\
\hline H12 & $50^{\circ} \mathrm{C}$ & $5 \mathrm{~h}$ & 2 & $1: 22$ \\
\hline H13 & $30^{\circ} \mathrm{C}$ & $5 \mathrm{~h}$ & 4 & $1: 22$ \\
\hline H14 & $50^{\circ} \mathrm{C}$ & $3 \mathrm{~h}$ & 4 & $1: 22$ \\
\hline H15 & $50^{\circ} \mathrm{C}$ & $3 \mathrm{~h}$ & 4 & $1: 44$ \\
\hline H16 & $50^{\circ} \mathrm{C}$ & $3 \mathrm{~h}$ & 4 & $1: 88$ \\
\hline
\end{tabular}

$\mathrm{E}: \mathrm{S}=$ Relação enzima:substrato; CA = carvão ativado

\section{Remoção de fenilalanina dos hidrolisados protéicos de leite}

A Phe foi removida dos hidrolisados protéicos de leite pela utilização do CA como meio adsorvente. Foi empregado o procedimento de passagem por coluna, desenvolvido no mesmo laboratório do presente trabalho [8]. O CA foi hidratado com água destilada por $10 \mathrm{~min}$ sob agitação constante e, em seguida, colocado em seringa descartável de $10 \mathrm{~mL}$ contendo filtro de nylon com lã de vidro. A coluna de carvão ativado foi montada colocando-se primeiro o carvão de menor granulometria, seguido pelo de média e 
por último o de maior granulometria. Em sequência, os hidrolisados foram passados pela coluna em quantidade suficiente para atingir a relação proteína:CA desejada, e submetidos à pressão (compressor Diapump, Fanem, mod. 089-A, série BE11778, São Paulo, SP, Brasil), tendo sido recolhidos os eluatos.

Efeito de alguns parâmetros sobre o preparo dos hidrolisados protéicos com baixo teor de fenilalanina

$\mathrm{O}$ efeito da temperatura foi avaliado testando-se os valores de $30{ }^{\circ} \mathrm{C}$ e $50{ }^{\circ} \mathrm{C}$. O efeito do tempo de reação foi testado utilizando-se os valores de $1 \mathrm{~h} 30 \mathrm{~min}, 3 \mathrm{~h}$ e $5 \mathrm{~h}$. Para o estudo da influência da relação enzima:substrato foram utilizadas as relações de 1:100, 2:100 e 4:100. Finalmente, o efeito da relação proteína:CA, foi estudado nas seguintes proporções 1:22, 1:44 e 1:88 (Tabela $1)$.

\section{Avaliação da eficiência da remoção de fenilalanina}

A avaliação da eficiência de remoção de Phe, pelo CA, foi realizada pela medida do teor de Phe livre, no leite e seus hidrolisados, após tratamento com CA, empregando-se a espectrofotometria derivada segunda [25]. As amostras foram submetidas à hidrolise ácida $\left(\mathrm{HCl}\right.$ a $\left.5,7 \mathrm{~mol} / \mathrm{L}, 110{ }^{\circ} \mathrm{C}, 24 \mathrm{~h}\right)$ e, após ajuste do $\mathrm{pH}$ para 6,0 , com solução de fosfato de sódio bibásico $(1 \mathrm{~mol} / \mathrm{L})$, foram submetidas às leituras de absorvância na faixa de 250 a 280 nm. Foram traçados os espectros de derivada segunda (Espectrofotômetro CECIL modelo CE2041, Buck Scientific, Hanslope, Inglaterra) e a área do terceiro pico negativo foi usada para calcular a quantidade de Phe presente nas amostras, empregando-se a curva padrão. O software GRAMS-UV (Galactic Industries Corporation, Salem, EUA) foi utilizado para traçar os espectros da derivada segunda.

Para a curva padrão, soluções estoques de Phe $\left(6,05 \times 10^{-4} \mathrm{~mol} / \mathrm{L}\right)$, Tyr $\left(5,52 \times 10^{-4}\right.$ $\mathrm{mol} / \mathrm{L})$ e $\operatorname{Trp}\left(4,90 \times 10^{-4} \mathrm{~mol} / \mathrm{L}\right)$ foram preparadas em tampão fosfato de sódio a 0,01 $\mathrm{mol} / \mathrm{L}(\mathrm{pH}$ 6,0). Em seguida, $10 \mathrm{~mL}$ de cada uma destas soluções foram misturados e a solução obtida foi diluída, sucessivamente, de maneira a se obter concentrações de Phe variando de 0,067 a 2,018 x $10^{-4} \mathrm{~mol} / \mathrm{L}$. A eficiência da remoção de Phe foi calculada de acordo com a equação (1)

\% Remoção de Phe $=$ teor de Phe inicial - teor de Phe final $\times 100$ teor de Phe inicial

onde,

Teor de Phe inicial = teor de Phe no leite

Teor de Phe final $=$ teor de Phe no hidrolisado, após tratamento com carvão ativado

\section{Análise estatística}

Todos os experimentos foram realizados em três repetições e as análises foram realizadas em triplicata. Para comparar a porcentagem de remoção de fenilalanina dos hidrolisados protéicos, utilizou-se a Análise de Variância (ANOVA fator único) e o Teste de Duncan para comparação de médias, ambos a $5 \%$ de probabilidade [32].

\section{RESULTADOS E DISCUSSÃO}

\section{COMPOSIÇÃO QUÍMICA DO LEITE}

Os dados referentes à composição química do leite estão apresentados na Tabela 2. Observa-se que, embora o emprego de diferentes métodos de análise, assim como o fato de que diversos fatores são capazes de influenciar a composição química do leite [33,34], os resultados obtidos estão muito próximos dos descritos na literatura e dos citados no rótulo do produto. Os dados da literatura utilizados para comparação de resultados referem-se a trabalhos realizados com leite integral UHT, sendo que no de NOGUEIRA (2007) [35] foram utilizadas as mesmas metodologias do presente trabalho. 
Tabela 2

Composição química do leite

\begin{tabular}{lcccc}
\hline $\begin{array}{c}\text { Componentes } \\
(\mathrm{g} / 100 \mathrm{~g})\end{array}$ & Resultados $^{1}$ & Rótulo $^{2}$ & TBCA $^{3}$ & NOGUEIRA $^{4}$ \\
\hline Umidade & 88,58 & - & 86,68 & 88,26 \\
Proteínas & 2,99 & 3,10 & 2,97 & 2,87 \\
Lipídeos & 2,72 & 3,00 & 3,04 & 2,81 \\
Cinzas & 0,67 & - & 0,79 & 0,76 \\
Carboidratos & 5,04 & 4,40 & 6,52 & 5,30 \\
\hline
\end{tabular}

Fonte: ${ }^{1}$ Resultados obtidos no presente trabalho. ${ }^{2}$ Dados disponíveis no rótulo do produto. ${ }^{3}$ TBCA - Tabeta Brasileira de Composição de Alimentos, USP (2008). ${ }^{4}$ NOGUEIRA (2007).

\section{EFICIÊNCIA DA REMOÇÃO DE FENILALANINA}

Os resultados obtidos para a remoção de Phe dos diferentes hidrolisados protéicos de leite estão expostos na Tabela 3, onde os valores estão apresentados em termos de porcentagem de remoção de Phe e em teor final de Phe $(\mathrm{mg} / 100 \mathrm{~mL}$ de leite), sendo esta última, a forma mais apropriada para os cálculos de adequação das prescrições dietéticas de substitutos protéicos destinados a fenilcetonúricos, além de atender a regulamentação técnica que normatiza a rotulagem nutricional de alimentos [37,38]. O teor de Phe encontrado no leite foi de $153 \mathrm{mg} / 100 \mathrm{~mL}$, resultado bastante semelhante aos encontrados na literatura que foram de $157 \mathrm{mg} / 100 \mathrm{~mL}$ e $173 \mathrm{mg} / 100 \mathrm{~mL}$, relatados por VERRUMA e SALGADO (1994) [39] e LAURINDO et al. (1992) [40], respectivamente, para leite de vaca integral.

Como pode ser observado, o carvão ativado se mostrou eficaz na remoção de fenilalanina de leite hidrolisado pela ação da protease do Aspergillus sojae, sendo que o percentual de remoção variou entre $16,3 \%$ e $64,6 \%$, obtendo um teor final de Phe entre $54,2 \mathrm{mg}$ e $128,1 \mathrm{mg}$ de Phe por $100 \mathrm{~mL}$ de leite. Dentre todas as condições de hidrólise testadas, 11 delas $(\mathrm{H} 2, \mathrm{H} 4$, de $\mathrm{H} 7$ a $\mathrm{H} 9$ e de H11 a H17) deram origem a um leite com baixo teor de Phe que poderia ser utilizado na dieta de pacientes fenilcetonúricos, pois, segundo a legislação brasileira, o limite máximo de Phe permitido em formulações dietéticas destinadas a estes pacientes é de 100 $\mathrm{mg}$ de $\mathrm{Phe} / 100 \mathrm{~mL}$ de produto. Vale, ainda, ressaltar que as proteínas deste leite estão hidrolisadas, sendo esta a forma em que estes nutrientes são mais rapidamente absorvidos pelo organismo, por apresentarem menor osmolaridade, melhor tolerância e aceitação, em relação às misturas de aminoácidos livres que são comumente utilizadas na dieta destes pacientes [41].

Tabela 3

Percentual de remoção e teor final de fenilalanina dos hidrolisados protéicos de leite

\begin{tabular}{ccc}
\hline Hidrolisados & $\begin{array}{c}\text { Remoção de Phe } \\
(\%)\end{array}$ & $\begin{array}{c}\text { Teor final de Phe } \\
(\mathrm{mg} / 100 \mathrm{~mL} \text { de leite })\end{array}$ \\
\hline H1 & $31,8^{\mathrm{gh}}$ & 104,5 \\
H2 & $35,4^{\mathrm{efg}}$ & 99,0 \\
H3 & $30,1^{\mathrm{h}}$ & 107,1 \\
H4 & $51,8^{\mathrm{c}}$ & 73,8 \\
H5 & $33,5^{\mathrm{gh}}$ & 101,9 \\
H6 & $16,3^{\mathrm{i}}$ & 128,1 \\
H7 & $42,7^{\mathrm{d}}$ & 87,8 \\
H8 & $39,3^{\mathrm{de}}$ & 93,0 \\
H9 & $48,3^{\mathrm{c}}$ & 79,2 \\
H10 & $31,2^{\mathrm{gh}}$ & 105,4 \\
H11 & $56,4^{\mathrm{b}}$ & 66,7 \\
H12 & $42,4^{\mathrm{d}}$ & 88,2 \\
H13 & $52,0^{\mathrm{c}}$ & 73,5 \\
H14 & $64,6^{\mathrm{a}}$ & 54,2 \\
H15 & $36,8^{\text {ef }}$ & 96,7 \\
H16 & $39,1^{\text {de }}$ & 93,3 \\
\hline
\end{tabular}

Phe=fenilalanina. Teor final de Phe $=$ teor de Phe dos hidrolisados após tratamento com carvão ativado. Médias indicadas por letras iguais não diferem entre si a $5 \%$ de probabilidade pelo teste de Duncan.

Em estudos realizados no mesmo laboratório do presente trabalho, a Phe foi removida do leite, sendo nestes casos, utilizado como matéria-prima na forma de pó e desnatado [5,8]. Além disso, as condições experimentais utilizadas foram diferentes, principalmente as relacionadas à concentração da matéria-prima $(0,35 \mathrm{~g} / 100 \mathrm{~mL})$, tipo e modo de emprego das enzimas (protease de Aspergillus oryzae - AO, associada com papaína - PA), relação E:S $(1: 100 \mathrm{AO}+2: 100$ PA, 10:100 AO + 20:100 PA, para LOPES et al., 2006 [5] e SOARES et al., 2006 [8],

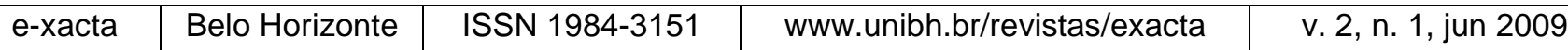


respectivamente) e relação proteína:CA (1:118 e 1:90, para LOPES et al., 2006 [5] e SOARES et al., 2006 [8], respectivamente). Acrescenta-se, ainda, que no estudo de LOPES et al. (2006) [5], o CA foi utilizado em solução. Assim, neste último trabalho foi possível obter até $99 \%$ de remoção de Phe, enquanto que no estudo de SOARES et al. (2006) [8] o maior valor obtido foi de $98 \%$, resultados estes bem superiores ao máximo obtido no presente trabalho. Ressalta-se, entretanto, que o emprego de uma solução muito diluída de matéria-prima (24 vezes menos concentrada do que a do presente trabalho), assim como de uma quantidade de CA muito elevada (até 5 vezes maior do que a do presente trabalho) tornariam o processo economicamente inviável para ser adaptado em larga escala. Acrescenta-se, ainda, as desvantagens econômicas e tecnológicas de se utilizar, como no estudo de SOARES et al., 2006 [8], valores muito elevados de relação E:S (10:100 AO + 20:100 PA).

Não foram encontrados na literatura dados de outros autores sobre a remoção de Phe de leite. Apenas dois trabalhos estudaram a remoção de Phe da principal proteína do leite. Assim, LOPEZ-BAJONERO et al. (1991) [42] removeram $92 \%$ de Phe de hidrolisados protéicos de caseína, obtidos pela ação de uma protease do Aspergillus oryzae $(\mathrm{E}: \mathrm{S}=1: 100,5 \mathrm{~h}$ de reação), seguida da papaína (E:S = 2:100, 21 h de reação), tratados com CA (em uma relação de $3 \mathrm{~g}$ de CA por $\mathrm{g}$ de caseína). Já MOSZCZYNSKI \& IDZIAK (1993) [43], utilizando um sistema de três enzimas (quimotripsina, carboxipeptidase A e leucina aminopeptidase,), todas empregadas em uma relação E:S de 1:100, a uma temperatura de $40{ }^{\circ} \mathrm{C}$, durante $72 \mathrm{~h}$ de reação e a um $\mathrm{pH}$ de 8,6, também removeram, através do CA (375 mg de CA para $10 \mathrm{~mL}$ de hidrolisado) , 89,5\% de Phe de hidrolisados de caseína. Cabe ressaltar que em ambos os trabalhos foram utilizados tempos extremamente longos de reação ( $26 \mathrm{~h}$ e $72 \mathrm{~h}$, respectivamente), tornando tais métodos inviáveis para aplicação em larga escala, além de elevar a possibilidade de uma contaminação microbiana.

\section{EFEITO DE ALGUNS PARÂMETROS SOBRE A REMOÇÃO DE FENILALANINA}

Todos os parâmetros foram analisados levando-se em consideração a redução dos custos do processo para adaptação em larga escala. Assim, o emprego de uma menor relação E:S está associado à utilização de menor quantidade de enzima necessária para a hidrólise; o de uma menor temperatura e tempo de reação está associado à redução de formação de produtos de degradação, além de menor consumo de energia; o de uma menor quantidade de carvão ativado (maior relação proteína:CA), implica em menores gastos, por ser o insumo de maior custo utilizado no processo.

\section{Efeito do tempo de reação}

Para se avaliar o tempo de reação sobre a remoção de Phe, os hidrolisados foram divididos em quatro grupos (Figura 1), visando manter constantes a temperatura e a relação enzima:substrato (E:S): grupo $1=30{ }^{\circ} \mathrm{C}$ e $1: 100$; grupo $2=50^{\circ} \mathrm{C}$ e $1: 100$; grupo $3=30$ ${ }^{\circ} \mathrm{C}$ e $2: 100$ e grupo $4=50{ }^{\circ} \mathrm{C}$ e $2: 100$.

Observa-se na Figura 1 que a vantagem da utilização de um menor tempo de reação ocorreu em todos os casos do grupo 2 (5h para $3 \mathrm{~h}$ e $3 \mathrm{~h}$ para $1 \mathrm{~h} 30 \mathrm{~min}$ ) e em um caso do grupo 4 (5h para $3 \mathrm{~h}$ ), pois obteve-se maior remoção de Phe. Para o grupo 1, a redução do tempo de reação não apresentou diferença significativa entre os resultados obtidos e, apenas ao se trabalhar à temperatura de $30{ }^{\circ} \mathrm{C}$ e $\mathrm{E}: \mathrm{S}$ de 2:100 (grupo 3), o emprego do tempo de reação mais elevado (5h) foi necessário para se obter a maior remoção de Phe.

Teoricamente, não seria esperado que o emprego de um menor tempo de reação não alterasse ou levasse a uma maior remoção de Phe. Entretanto, os resultados aqui obtidos demonstraram que, pelo menos, em algumas situações isto pode ocorrer. Assim, no grupo 1 observou-se esta manutenção nos resultados de remoção de Phe com a utilização de um menor tempo de reação. Uma provável explicação 
para isto estaria associada ao fato de que alguns fatores poderiam estar contribuindo para a redução da taxa de hidrólise, com o passar do tempo.

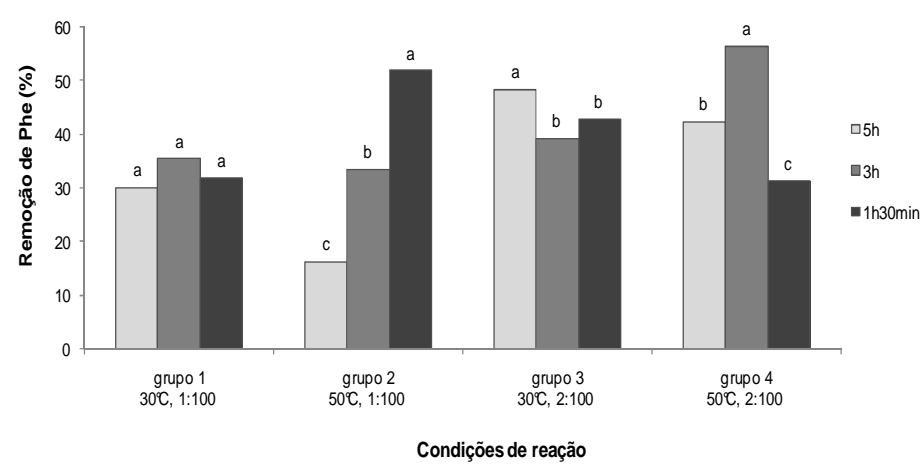

Figura 1. Efeito do tempo de reação sobre a remoção de Phe dos hidrolisados protéicos. 1:100 e 2:100 = valores para relação E:S. Médias indicadas por letras iguais, para um mesmo grupo, não diferem entre si a $5 \%$ de probabilidade.

Assim, de acordo com GUAN et al. (2007) [44], dentre estes fatores encontram-se a redução das ligações peptídicas específicas para ação da enzima, a inativação enzimática e a competição entre a proteína nativa e os peptídeos formados constantemente durante a hidrólise. Já nos dois casos do grupo 2 (5h para $3 \mathrm{~h}$ e para $1 \mathrm{~h} 30 \mathrm{~min})$ e em um caso do grupo 4 (3h para 1h30min), ocorreu uma elevação da remoção de Phe. Nestes casos, ao se utilizar um maior tempo de reação pode ter havido uma maior desnaturação protéica impedindo a ação enzimática, e complexação das proteínas já hidrolisadas com a lactose e o cálcio, impedindo uma remoção mais eficiente de Phe [44].

Não foram encontrados na literatura trabalhos que avaliassem o efeito do tempo de hidrólise sobre a remoção de Phe de hidrolisados protéicos.

\section{Efeito da temperatura de reação}

Para esta avaliação, os hidrolisados foram divididos em seis grupos (Figura 2), visando manter constantes a relação $\mathrm{E}: \mathrm{S}$ e o tempo de reação: grupo $1=1: 100$ e $1 \mathrm{~h} 30 \mathrm{~min}$; grupo $2=1: 100$ e $3 \mathrm{~h}$; grupo $3=1: 100$ e $5 \mathrm{~h}$; grupo $4=2: 100$ e 1 h30min; grupo $5=2: 100$ e $3 \mathrm{~h}$ e grupo $6=2: 100$ e $5 \mathrm{~h}$.

Observa-se na Figura 2 que a vantagem do emprego da menor temperatura de reação $\left(30^{\circ} \mathrm{C}\right)$ ocorreu para os grupos 3,4 e 6 , pois obteve-se maior remoção de Phe. Para o grupo 2 , não se encontrou diferença significativa entre os resultados obtidos para as duas temperaturas testadas. Por outro lado, a utilização da temperatura de $50{ }^{\circ} \mathrm{C}$ foi benéfica para os grupos 1 e 5, levando a uma maior remoção de Phe que a de $30^{\circ} \mathrm{C}$.

Era de se esperar que, trabalhando com valores de temperatura dentro ou próximo da faixa ótima de atuação da enzima, como é o caso de $50{ }^{\circ} \mathrm{C}$, poderia favorecer a hidrólise protéica e, consequentemente, a liberação e a remoção de Phe. Entretanto, para a maioria dos casos estudados isto não foi observado (grupos 2, 3, 4 e 6) e o emprego da temperatura de $30^{\circ} \mathrm{C}$ foi mais vantajoso, o que é interessante do ponto de vista econômico. Estes resultados indicam que fatores, tais como o grau de desnaturação protéica, associado à quantidade de enzima e tempo de reação, podem interferir nos resultados.

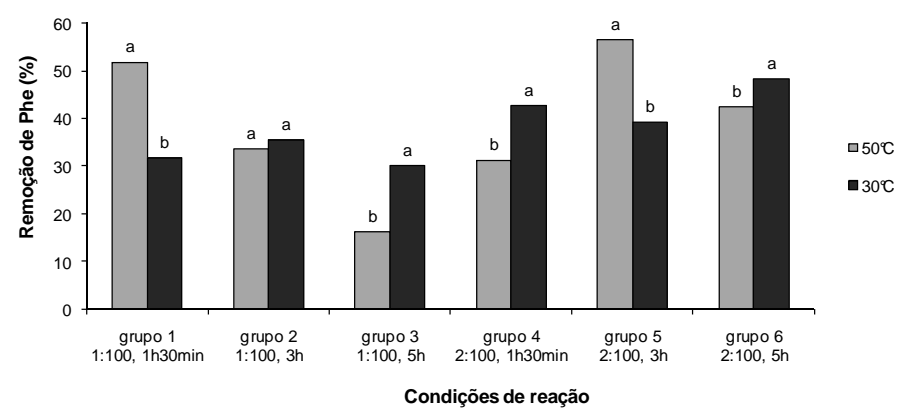

Figura 2. Efeito da temperatura sobre a remoção de Phe dos hidrolisados protéicos. 1:100 e 2:100 = valores para relação E:S. Médias indicadas por letras iguais, para um mesmo grupo, não diferem entre si a $5 \%$ de probabilidade.

Não foram encontrados na literatura dados de outros autores sobre a influência da temperatura de hidrólise sobre a remoção de Phe de leite. No entanto, este parâmetro foi, anteriormente, avaliado no mesmo laboratório do presente trabalho, ao se utilizar a papaína no preparo de feijão com baixo teor de Phe. Assim, LOPES Jr. (2008) [10], observou que o 
emprego de maior temperatura $\left(25^{\circ} \mathrm{C}\right.$ e $\left.50^{\circ} \mathrm{C}\right)$ influenciou positivamente a remoção de Phe, obtendo resultados de $69,9 \%$ e $81,5 \%$, respectivamente, ao se empregar a protease de Papaya carica, na relação E:S de 10:100, por 5 horas.

\section{Efeito da relação enzima:substrato}

Para esta avaliação, os hidrolisados foram divididos em seis grupos (Figura 3), mantendo-se constantes os valores de temperatura e tempo de reação: grupo $1=30$ ${ }^{\circ} \mathrm{C}$ e $1 \mathrm{~h} 30 \mathrm{~min}$; grupo $2=30^{\circ} \mathrm{C}$ e $3 \mathrm{~h}$; grupo $3=$ $30{ }^{\circ} \mathrm{C}$ e $5 \mathrm{~h}$; grupo $4=50^{\circ} \mathrm{C}$ e $1 \mathrm{~h} 30 \mathrm{~min}$; grupo $5=50^{\circ} \mathrm{C}$ e $3 \mathrm{~h}$ e grupo $6=50^{\circ} \mathrm{C}$ e $5 \mathrm{~h}$.

Foram testadas as relações E:S de 1:100 e 2:100 em todos os grupos, enquanto que a relação E:S de 4:100 somente foi testada nos grupos 3 e 5, a fim de avaliar a influência do emprego de uma maior quantidade de enzima, apenas nas condições em que se obteve os maiores teores de remoção, a $30^{\circ} \mathrm{C}$ e a $50{ }^{\circ} \mathrm{C}$, respectivamente.

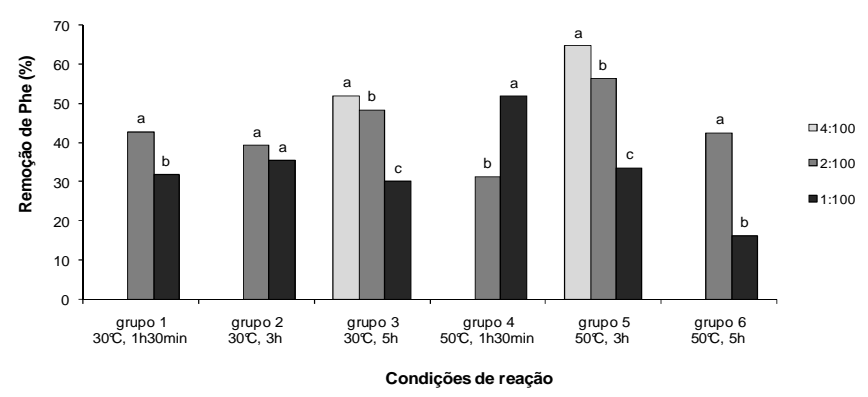

Figura 3: Efeito da relação E:S sobre a remoção de Phe dos hidrolisados protéicos. Médias indicadas por letras iguais, para um mesmo grupo, não diferem entre si a $5 \%$ de probabilidade.

Como pode ser observado na Figura 3, a vantagem da utilização de uma menor quantidade de enzima (menor relação E:S) ocorreu apenas para o grupo 4 (de 2:100 para 1:100), e não apresentou diferença significativa para o grupo 2. Já para os grupos $1,3,5$ e 6 , o emprego de uma maior relação E:S (2:100 ou 4:100) foi necessário para se obter uma maior remoção de Phe.
Em outros estudos realizados anteriormente no Laboratório de Bromatologia/Pesquisa, utilizando-se como matéria-prima leite em pó desnatado, diversas enzimas e condições de hidrólise protéica foram testadas, e os valores reportados apresentaram a mesma variação do presente trabalho, ou seja, em alguns casos, o emprego de uma maior relação E:S foi vantajoso, em outros não afetou ou foi prejudicial para a remoção de Phe $[5,8]$.

O conjunto destes resultados demonstra que, apesar de se esperar, teoricamente, que o emprego de uma maior relação E:S, uma maior temperatura e maior tempo de reação, leve a um maior grau de hidrólise e, consequentemente, a uma maior exposição de Phe e a um menor teor final de Phe, na prática, esse procedimento é bem mais complexo do que o esperado e depende de outros fatores, tais como tipo e atividade da enzima, tipo e concentração de substrato e $\mathrm{pH}$.

\section{Efeito da relação proteína:carvão ativado}

A avaliação do efeito da relação proteína:carvão sobre a remoção de Phe foi realizada comparando-se os resultados obtidos para os hidrolisados H14 (relação proteína:CA = 1:22), H15 (relação proteína:CA = 1:44) e H16 (relação proteína:CA $=1: 88$ ).

Observa-se na Figura I.4 que a vantagem da utilização de uma menor quantidade de CA (maior relação proteína:CA) foi encontrada, uma vez que a maior remoção de Phe $(64,6 \%)$ foi obtida com uma relação proteína:CA de $1: 22$, a qual foi bem superior às encontradas ao se utilizar maiores quantidades de carvão (1:44, 36,8\% e $1: 88,39,1 \%)$.

Em estudo do mesmo Laboratório do presente trabalho que avaliou o efeito da relação proteína:CA na remoção de Phe de leite, na forma em pó e desnatado, foi mostrado que, ao contrário do presente trabalho, o emprego de diferentes quantidades de carvão ativado (relações proteína C:A de $1: 118,1: 90$ e 1:60) não afetou a remoção de Phe (média de 97\%) [8]. 


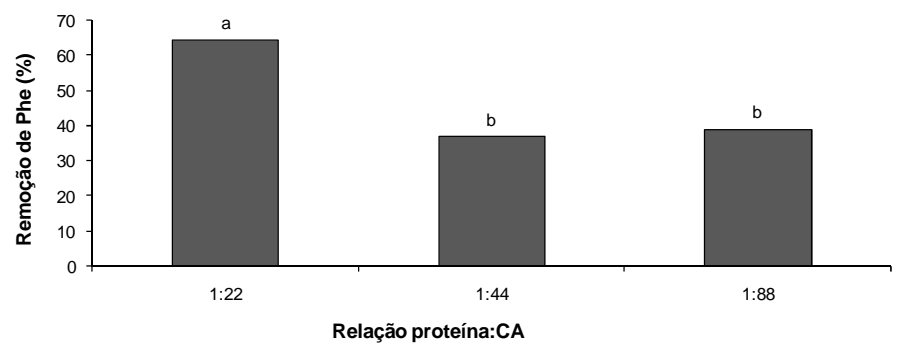

Figura 4: Efeito da relação proteína:CA sobre a remoção de Phe dos hidrolisados protéicos. Médias indicadas por letras iguais não diferem entre si a $5 \%$ de probabilidade.

\section{CONCLUSÃO}

Empregando-se diversas condições de hidrólise das proteínas e quantidades variadas de CA como meio adsorvente, foi possível obter um leite com baixo teor de Phe $(54,2 \mathrm{mg} / 100 \mathrm{~mL})$ que poderia ser utilizado na dieta de pacientes fenilcetonúricos. $\mathrm{O}$ melhor resultado obtido foi aquele em que se utilizou o tempo de reação de $3 \mathrm{~h}$, a temperatura de 50 ${ }^{\circ} \mathrm{C}$, relação E:S de 4:100 e relação proteína:CA de 1:22, tendo atingido $64,6 \%$ de remoção de Phe.

\section{AGRADECIMENTOS}

Os autores agradecem ao CNPq, CAPES e FAPEMIG pelo apoio financeiro.

\section{REFERÊNCIAS BIBLIOGRÁFICAS}

[1] MIRA, N.V.M.; MARQUEZ, U.M.L. Importância do diagnóstico e tratamento da fenilcetonúria. Rev. Saúde Públ., v. 34, p. 8696, 2000.

[2] MONTEIRO, L.T.B.; CÂNDIDO, L.M.B. Fenilcetonúria no Brasil: evolução e casos. Rev. Nutr., v. 19, p. 381-387, 2006.

[3] KANUFRE, V.C.; SANTOS, J.S.; SOARES, R.D.L.; STARLING, A.L.P.; AGUIAR, M.J.B. Abordagem dietética para fenilcetonúria. Rev. Med. Minas Gerais, v. 11, n. 2, p. 129-134, 2001

[4] LOPES, D.C.F; DELVIVO, F. M.; SILVESTRE, M. P. C Use of activated carbon for removing phenylalanine from skim milk powder. Food Sci. Tech., v. 38, p. 447-453, 2004.

[5] LOPES, D.C.F.; DELVIVO, F.M.; SILVESTRE, M.P.C. Dietary Supplements for Phenylketonuria: removing Phe by activated carbon. Nutr. Food Sci., v. 36, n. 2, p. 96-104, 2006

[6] DE MARCO, L.M.; DELVIVO, F.M.; SILVA, V.D.M.; COELHO, J.V.; SILVESTRE, M.P.C. Uso do carvão ativado para remoção de fenilalanina de hidrolisados protéicos, obtidos pela ação da papaína imobilizada. Braz. J. Food Technol., v.8, n. 3, p. 210-219, 2005.

[7] CAPOBIANGO, M.; SILVA, V.D.M.; MACHADO, M.A.A.; COELHO, J.V.; SEGALL, S.D.; SILVESTRE, M.P.C. Ação da corolase pp e uso do carvão ativado na obtenção de hidrolisados protéicos de fubá de milho com baixo teor de fenilalanina. Rev. Bras. Nutr. Clín., v.21, n.4, p.259-266, 2006. [8] SOARES, R.D.L.; BIASUTTI, E.A.R.; CAPOBIANGO, M.; VIEIRA, C.R.; SILVA, V.D.M.; JANUÁRIO, J.N.; AGUIAR, M.Jb.; SILVESTRE, M. P. C. Preparation of enzymatic skim milk hydrolysates with low phenylalanine content. Acta Farmac. Bonaer., v. 25, p. 325-332, 2006.

[9] SILVA, V.D.M.; MARCO, L.M.; AFONSO, W.O.; LOPES, D.C.F.; JANUÁRIO, J.N.; AGUIAR, M.J; STARLING, A.L.P.; SILVESTRE, M.P.C. Preparation of low-phenylalanine whey hydrolysates, using papain and pancreatin immobilized on activated carbon and alumina. Amer. J. Food Technol., v. 2, p. 327-341, 2007.

[10] LOPES Jr., C.O. Extração protéica e obtenção de hidrolisados protéicos de feijão com baixo teor de fenilalanina. Belo Horizonte: Faculdade de Farmácia da UFMG. 2008. 81 p. (Dissertação, Mestrado em Ciência de Alimentos).

[11] SILVESTRE, M.P.C. ; VIEIRA, C.R.; SILVA, M.R. ; SILVA, M.C; LOPES Jr, C.O.; SILVA, V.D.M. Use of an enzymatic process for extracting and hydrolysing rice proteins aiming phenylalanine removal. Int. J. Food Engineer., v. 5, n. 1, art. 2, 2009. \begin{tabular}{l|l|l} 
e-xacta & Belo Horizonte & ISSN 1984-3151
\end{tabular} www.unibh.br/revistas/exacta 
[12] DELVIVO, F.M.; VIEIRA, C.R.; BIASUTTI, E.A.R.; AFONSO, W.O.; SILVESTRE, M.P.C. Evaluating the effect of adsorption medium, hydrolytic parameters and ultrafiltration on the phenylalanine removal from pancreatic whey hydrolysates. Amer. J. Food Technol., v. 1, n. 2, p. 94-104, 2006.

[13] LOPES, D.C.F; DELVIVO, F.M.; JANUÁRIO, J.N.; AGUIAR, M.J.B.; STARLING, A.L.P.; SILVESTRE, M. P. C. Phenylalanine removal from whey hydrolysates. J. Food Techonol., v. 5, n. 2, p. 191-197, 2007.

[14] BIZZOTTO. C.S.; BIASUTTI, E.A.R.; SILVA, V.D.M.; AZEVEDO, K.V.; JUNQUEIRA, R.G. SILVESTRE, M.P.C. Uso da pancreatina e do carvão ativado no processo de preparo de hidrolisados protéicos de arroz com baixo teor de fenilalanina. Tecno-lóg., v. 10, p. 9-30, 2006.

[15] BIZZOTTO. C.S.; CAPOBIANGO, M.; BIASUTTI, E.A.R.; SILVA, V.D.M.; JUNQUEIRA, R.G. SILVESTRE, M.P.C. Hidrolisados protéicos de arroz com baixo teor de fenilalanina, obtidos pela ação da corolase pp e uso do carvão ativado. Rev. Ciên. Agrotec., v. 30, p. 308-316, 2006.

[16] VIEIRA, C. R., LOPES Jr., C.O., RAMOS, C.S., CAPOBIANGO, M., SILVESTRE, M. P. C. Extração enzimática das proteínas da farinha de arroz. Ciênc. Tecnol. Alimen., v. 28, p. 599-606, 2008.

[17] DE MARCO, L.M.; DELVIVO, F.M.; SILVA, V.D.M.; COELHO, J.V. SILVESTRE, M.P.C. Imobilização da papaína em carvão ativado e em alumina, visando sua utilização no preparo de formulações dietéticas. Tecno-Lóg., v. 8, p. 83-89, 2004.

[18] GRANT, A.; BHATTACHARYYA, P.K. Application of derivative spectroscopy to the determination of chromatographic peak purity.

J. Chromatog. A, v.347, p.219-235, 1985.

[19] ICHIKAWA, T.; TERADA, H. Second derivate spectrophotometry as an effective tool for examining phenylalanine residues in proteins. Biochim. Biophys. Acta, v. 494, p. 267-270, 1977.

[20] ICHIKAWA, T.; TERADA, H. Estimation of state and amount of phenylalanine residues in proteins by second derivative spectrophotometry. Biochim. Biophys. Acta, v. 580, p. 120-128, 1979.

[21] ICHIKAWA, T.; TERADA, H. Determination of phenylalanine, tryptophan and tyrosine in a mixture of amino acids by second derivative spectrophotometry. Chem. Pharm. Bull., v.29, n.2, p.438-444, 1981.

[22] ICHIKAWA, T.; TERADA, H. Effect of dodecyl sulfate on the spectral properties of phenylalanil residues in serum albumin detected by second derivative spectrophotometry. Biochim. Biophys. Acta, v.671, n.1, p.33-37, 1981.

[23] SILVESTRE, M.P.C.; DAUPHIN, D.; HAMON, M. Application of uv absorbance and second-derivative spectrophotometry for analysing casein hydrolysates. Anal. Chim. Acta, v. 282, p. 603-612, 1993.

[24] DELVIVO, F.M.; SILVA, V.D.M.; MORAIS, H.A.; FIGUEIREDO, A.F.S.; AGUIAR, M.J.B.; COELHO, J.V.; SILVESTRE M.P.C. Desenvolvimento de formulação dietética para fenilcetonúricos à base de hidrolisados de soro de leite. Rev. Bras. Nutr. Clin., v.20, n.3, p.117-126, 2005. [25] LOPES, D.C.F; DELVIVO, F.M.; SILVESTRE, M.P.C. Use of activated carbon for removing phenylalanine from skim milk powder. Food Sci. Technol., v. 38, n. 5, p. 447-453, 2005.

[26] SILVA, V.D.M.; DE MARCO, L.M.; DELVIVO, F.M.; AGUIAR, M.J.B.; COELHO, J.V.; SILVESTRE, M.P.C. Emprego da pancreatina imobilizada no preparo de hidrolisados de soro de leite com teor reduzido de fenilalanina. Alim. Nutr., v.16, n.1, p.21-31, 2005.

[27] SILVA, V.D.M.; DE MARCO, L.M.; DELVIVO, F.M.; COELHO, J.V.; SILVESTRE, M.P.C. Imobilização da pancreatina em carvão ativado e em alumina, visando sua utilização no preparo de formulações dietéticas. Acta Sci. Health Sci., v.27, n.2, 2005.

[28] AOAC (Association of Official Analytical Chemists). Official Methods of Analysis.

16. ed. 3. rev. Arlington: AOAC International, 1995. 1141p. 
[29] GREENFIELD, H.; SOUTHGATE, D.A.T. Food composition data: production, management and use. London: Chapman \& Hal, 1992. 243p. Disponível em: http://www.fcf.usp.br/tabela/qual.asp. Acesso em: 31/10/2007.

[30] BLIGH, E.G. \& DYER, W.J. A rapid method of total lipid extraction and purification. Can. J. Biochem. Physiol., v. 37, p. 911-917, 1959.

[31] DIAS, D.R.; VILELA, D.M; SILVESTRE, M.P.C.; SCHWAN, R.F.. Alkaline protease from Bacillus sp. isolated from coffee bean grown on cheese whey. World J. Microbiol. Biotechnol., v. 24, p. 2027-2034, 2008.

[32] PIMENTEL-GOMES, F. Curso de estatística experimental. 14 ed. Piracicaba, 2000. 477p.

[33] SGARBIERI, V.C. Proteínas em alimentos protéicos: propriedades, degradação, modificação. São Paulo: Varela, 1996. 517 p.

[34] ORNELLAS, L.H. Técnica dietética: seleção e preparo de alimentos. 7 ed. São Paulo: Atheneu, 2001, 330 p.

[35] NOGUEIRA, F.A.G. Disponibilidade de cálcio em leite adicionado de outros alimentos. Piracicaba: Escola Superior de Agricultura Luiz de Queiroz. 2007. 118 p. (Dissertação, Mestrado em Ciência e Tecnologia de Alimentos).

[36] TBCA - USP - Tabela brasileira de composição de alimentos. Faculdade de Ciências Farmacêuticas da Universidade de São Paulo, versão 5.0. 2008. Disponível em < http://www.fcf.usp.br/tabela/> Acesso em: 24 de outubro de 2008.

[37] BRASIL. Ministério da Saúde. Portaria n. 847 de 31 de outubro de 2002. Aprova o protocolo clínico e diretrizes terapêuticas fenilcetonúria - fórmulas de aminoácidos isenta de fenilalanina. Diário Oficial da
República Federativa do Brasil, Poder Executivo, Brasília, DF, 04 novembro 2002. [38] BRASIL. Ministério da Saúde. Agência Nacional de Vigilância Sanitária. Resolução RDC n. 360. Aprova Regulamento Técnico sobre Rotulagem Nutricional de Alimentos Embalados, tornando obrigatória a rotulagem nutricional. Diário Oficial da República Federativa do Brasil, Poder Executivo, Brasília, DF, 26 dezembro 2003.

[39] VERRUMA, M.R.; SALGADO, J.M. Análise química do leite de búfala em comparação ao leite de vaca. Sci. Agic, v. 51, n. 1, p. 131-137, 1994.

[40] LAURINDO, V.M; CALIL, T.; LEONE, C.R.; RAMOS, J.L.A. Composição nutricional de colostro de mães de recém-nascidos de termo adequados e pequenos para a idade gestacional. II Composição nutricional do leite humano nos diversos estágios da lactação. Vantagens em relação ao leite de vaca. Pediatria (São Paulo), v. 14, p. 14-23, 1992. [41] FRENHANI, P.B.; BURINI, R.C. Mecanismos de absorção de aminoácidos e oligopeptídios. Controle e implicações na dietoterapia humana. Arq Gastroenterol, v. 36, n. 4, p. 227-236, 1999

[42] LOPEZ-BAJONERO, L.J.; LARACALDERON, P.; GALVEZ-MARISCAL, A.; VELASQUEZ-ARELLANO, A.; LOPEZMUNGUIA, A. Enzymatic production of a low-phenylalanine product from skim milk powder and caseinate. J. Food Sci., v. 56, p. 938-942, 1991.

[43] MOSZCZYNSKI, P.; IDIZIAK, J. Preparation of enzymatic hydrolysates of casein depleted in phenylalanine. App. Biochem. Microbiol., v. 29, p. 302-306, 1993. [44] GUAN, X.; YAO, H.; CHEN, Z; SHAN, L.; ZHANG, M. Some functional properties of oat bran protein concentrate modified by tripsin. Food Chem., v. 101, p. 163-170, 2007. 